\title{
APROXIMAÇÃO DAS QUESTÕES SOCIOCIENTÍFICAS EM UM INSTRUMENTO DE AVALIAÇÃO ESCOLAR EM CIÊNCIAS: UMA ESTRATÉGIA PARA IDENTIFICAR VULNERABILIDADE DOS ADOLESCENTES ÀS IST/AIDS
}

\author{
Approximation of socio-scientific issues in a school science assessment tool: a \\ strategy to identify adolescents' vulnerability to STI/AIDS
}

\author{
Manoel Messias Santos Alves* \\ Alice Alexandre Pagan**
}

\begin{abstract}
Resumo: O objetivo deste artigo está centrado na elaboração de um instrumento de avaliação escolar em ciências, inspirado em questões sociocientíficas (QSC), para identificar níveis de vulnerabilidade às IST/AIDS entre o público adolescente. Mediante uma abordagem qualitativa e com viés exploratório, o instrumento de avaliação desenvolvido neste estudo foi submetido a um processo de validação de conteúdo, por meio da metodologia Delphi, e contou com a colaboração de um painel de especialistas composto por pesquisadores, professores e profissionais da área da saúde, bem como com a participação de estudantes matriculados no $3^{\circ}$ ano do Ensino Médio, para as etapas de validação semântica e aplicação piloto do questionário. $\mathrm{O}$ instrumento desenvolvido e validado corresponde a uma importante e inovadora estratégia para o ensino de ciências.
\end{abstract}

Palavras-chave: Educação em saúde. Educação sexual. Educação CTSA. Validação de conteúdo.

\begin{abstract}
The objective of this article is centered on the elaboration of a school science assessment instrument, inspired by socio-scientific issues (SSI), to identify levels of vulnerability to STI/AIDS among the adolescent public. Through a qualitative and exploratory approach, the evaluation instrument developed in this study was submitted to a content validation process, using the Delphi methodology and had the collaboration of a panel of experts composed of researchers, teachers and professionals in the field of education and of health, as well as the participation of students enrolled in the 3rd year of high school, for the stages of semantic validation and pilot application of the questionnaire. The developed and validated instrument corresponds to an important and innovative strategy for science teaching.
\end{abstract}

Keywords: Health education. Sex education. STSE Education. Content validation.

\footnotetext{
* Doutorando em Educação (PPGED/UFS). Mestre em Ensino de Ciências (PPGECIMA/UFS). Bacharel em Enfermagem e Licenciado em Ciências Biológicas. Universidade Federal de Sergipe (UFS). Orcid iD: https://orcid.org/0000-0002-4070-1691. E-mail: messyarts@hotmail.com.

** Professora Associada II do Departamento de Biologia da Universidade Federal de Sergipe (UFS). Licenciada em Ciências Biológicas pela UNEMAT (2002); Mestre em Educação pela UFMT (2004) e Doutora em Educação, área: Ensino de Ciências e Matemática, pela USP (2009). Orcid iD: http://orcid.org/0000-0002-9757-4304. Email: apagan.ufs@gmail.com.
} 


\section{Introdução}

Diante das novas perspectivas dos processos de ensino e aprendizagem da educação científica, engajadas com os pressupostos do pluralismo epistemológico, tem-se destacado cada vez mais a necessidade de construir instrumentos de avaliação escolar que, além do desenvolvimento de habilidades e competências cognitivas, contemplem, sobretudo, as esferas afetivas e comportamentais dos alunos, nas quais a educação em saúde assume um caráter social relevante em consonância com a ciência, a tecnologia e os demais aspectos socioambientais, políticos e econômicos.

Apesar de a educação em saúde ser um importante processo que permite aos alunos agirem ativamente no meio no qual estão inseridos, refletindo sobre como suas decisões podem repercutir em sua própria saúde e na da coletividade, reconhecemos que a inclusão dessa temática no espaço escolar ainda apresenta alguns entraves relacionados aos diferentes entendimentos acerca dos processos de saúde e doença, que envolvem questões de ordem teórica e epistemológica voltadas às abordagens biomédica e socioecológica da saúde. Nesse sentido, na medida em que o modelo biomédico prioriza curar os indivíduos doentes por meio de estratégias prescritivas e informativas, a abordagem socioecológica focaliza-se numa visão positiva e coletiva de saúde que, além dos aspectos biológicos, contempla o bem-estar biopsicossocial e ambiental em suas múltiplas dimensões (MARTINS, 2011; FERREIRA et al., 2014; MARTINS et al., 2017).

Nessa perspectiva, as Infecções Sexualmente Transmissíveis (IST) em geral, sobretudo a infecção pelo Vírus da Imunodeficiência Humana (HIV), que, se não for devidamente tratada, pode resultar na Síndrome da Imunodeficiência Adquirida (AIDS), são importantes problemas de saúde pública incidentes no mundo, sendo uma das temáticas da educação em saúde de maior relevância, devido à complexidade existente nas práticas pedagógicas que implicam tomada de posições frente aos agravamentos sociais. Assim, foi priorizada neste estudo uma abordagem socioecológica da saúde, em virtude de sua importância para a emancipação de alunos atuantes no contexto sociopolítico e ecológico do qual fazem parte, bem como suas relações com a abordagem Ciência, Tecnologia, Sociedade e Ambiente (CTSA) e demais abordagens teóricas (CONRADO; NUNES-NETO, 2018; MARTINS et al., 2018).

Trabalhar a temática sexualidade para se estabelecer uma relação entre os estilos de vida e vulnerabilidade dos adolescentes às IST pode envolver uma série de discussões e problemas controversos. Sendo assim, o presente artigo teve como objetivo central a elaboração de um instrumento de avaliação escolar em ciências, com aproximação das questões sociocientíficas (QSC), para identificar níveis de vulnerabilidade às IST/AIDS entre o público adolescente. Dessa forma, para que a educação sexual e demais temáticas da educação em saúde sejam inseridas numa perspectiva socioecológica, é necessário considerar aspectos socioeconômicos, culturais, ambientais, políticos e educacionais da saúde, tanto na esfera individual quanto na coletiva, inferindo que o uso de QSC pode contribuir com as perspectivas da educação CTSA e promover o desenvolvimento da capacidade crítica dos educandos.

Considerando que a maioria dos atuais sistemas nacionais e internacionais de avaliação escolar atribui a qualidade da educação ao aumento da proficiência dos estudantes nesses exames (BIZZO, 2015; MACHADO; ALAVARSE; ARCAS, 2015), buscamos quebrar esse paradigma por considerarmos que o entendimento de avaliação de qualidade não pode se restringir à aplicação de testes e provas com o intuito de averiguar o nível intelectual sobre determinados conteúdos conceituais, e sim levar em consideração também a elaboração de avaliações contextualizadas com as condições dos alunos e com o processo pedagógico da escola, envolvendo QSC tanto para contemplar os aspectos cognitivos quanto os não cognitivos, 
como as atitudes e seus componentes afetivos e comportamentais (ZABALA, 1998; SOUZA et al., 2017; ALVES; PAGAN, 2019).

\section{A educação CTSA e o ensino por QSC como estratégias pedagógicas inovadoras no ensino de ciências}

Entre as décadas de 1960 e 1970, diante da insatisfação acerca das relações e concepções tradicionais da ciência e da tecnologia frente aos problemas políticos e econômicos, surgiu um movimento de origem acadêmica e social conhecido como Ciência, Tecnologia e Sociedade (CTS), que, por sua vez, deu origem a um leque de discussões com diferentes enfoques em torno da relação entre a ciência e a tecnologia com o meio social, engajados na tomada de decisões conscientes e comprometidas com os problemas socioambientais (ZEIDLER et al., 2005; PEDRETTI; NAZIR, 2011). O movimento CTS culminou em novas tendências para o ensino, no qual a ciência e a tecnologia passaram a ser reconhecidas como processos sociais, carregados de valores (ZEIDLER et al., 2005; STRIEDER, 2008; PEDRETTI; NAZIR, 2011; CONRADO; NUNES-NETO, 2018; MARTINS et al., 2018).

É importante ressaltar que, apesar de algumas considerações acerca do meio ambiente estarem implicitamente incluídas nos contextos científicos, tecnológicos, socioculturais e políticos da educação CTS, recentemente, alguns autores (ZEIDLER et al., 2005; CONRADO, 2017; CONRADO; NUNES-NETO, 2018) mostraram uma maior preocupação com a gravidade da crise ambiental decorrente dos processos de produção - que muitas vezes assumem um caráter predatório e focado apenas no capitalismo -, sendo enfatizada, de maneira explícita, a dimensão ambiental nas abordagens CTS, defendendo, assim, a inclusão do " $A$ " de ambiente e promovendo a expressão CTSA, visto que, de acordo com Conrado e Nunes-Neto (2018, p. 82), "não é suficiente assumir que considerações sobre o ambiente já estão, diretamente, presentes quando falamos da sociedade".

Entretanto, Mortimer (2002) e Zeidler et al. (2005) já vinham observando que muitas vezes, a educação CTSA praticada no âmbito escolar não estava completa e coerentemente inserida no desenvolvimento sociológico dos estudantes, deixando de considerar explicitamente os aspectos psicológicos e epistemológicos da educação. $\mathrm{O}$ fato de as abordagens CTSA terem ficado, de certa forma, um tanto marginalizadas dos currículos de ensino de ciências nos últimos anos, sobretudo no aspecto avaliativo, nos motivou a pensar na elaboração de um instrumento de avaliação que, além da aprendizagem científica e tecnológica, trouxesse uma certa aproximação com as QSC, para que essas abordagens possam ser substancialmente melhoradas, visando estimular e promover de maneira mais intensa o desenvolvimento intelectual e o senso crítico dos alunos diante dos problemas controversos existentes em cada contexto sociocultural e ambiental em que estão inseridos (ZEIDLER et al., 2005; ZEIDLER; NICHOLS, 2009).

Embora muitos estudos envolvendo QSC estejam conceitualmente relacionados com as pesquisas anteriores sobre a educação CTSA, abordaremos nesta seção os principais pressupostos e diferenciações de ambos os movimentos, que, apesar de distintos, podem apresentar abordagens semelhantes e ao mesmo tempo diferenciadas, observando-se que, de acordo com Zeidler et al. (2005), a educação QSC pode possibilitar de maneira mais eficaz, o estabelecimento de interconexões entre as crenças pessoais dos alunos com a ciência, a tecnologia, o contexto social e o meio ambiente. 


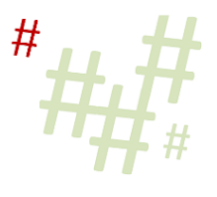

\subsection{Pressupostos e tendências da educação CTSA: um panorama geral}

Em contraposição à racionalidade técnica propagada pela educação científica tradicional da época, o movimento CTSA buscava a alfabetização científica e tecnológica para que os cidadãos fossem capazes de tomar decisões fundamentadas e ações responsáveis (ZEIDLER et al., 2005; PEDRETTI; NAZIR, 2011). A educação tradicional possui como atributos o enfoque na transmissão de conhecimentos científicos; a descontextualização socioambiental; o conceitualismo; e o tecnicismo, sendo que tais fatores delimitam "à crítica, à criatividade ou à reflexão sobre valores, ideologias e contextos relacionados à ciência e à tecnologia" (CONRADO; NUNES-NETO, 2018, p. 79). Dessa forma, os estudos CTSA, no campo da educação, desde sua origem, preconizam um ensino de ciências mais crítico, dinâmico e contextualizado, a fim de contribuir para a promoção e a participação da sociedade no desenvolvimento científico e tecnológico (SANTOS; MORTIMER, 2002; STRIEDER, 2008).

É indiscutível o fato de que a educação CTSA tenha contribuído inquestionavelmente para que a ciência seja compreendida como "uma atividade humana relacionada a um contexto sociocultural e ambiental mais complexo e abrangente, no qual há influências mútuas entre ciência, tecnologia, sociedade e ambiente" (CONRADO; NUNES-NETO, 2018, p. 83). No entanto, atualmente tem crescido na literatura científica o número de publicações exaltando algumas críticas sobre esse movimento, principalmente no que se refere às inclinações ideológicas e à diversidade de pressupostos e formulações em torno da educação CTSA, resultando numa série de divergências internas e dificuldade em compreender seus enfoques e tendências (AIKENHEAD, 2003; ZEIDLER et al., 2005; STRIEDER, 2008; PEDRETTI; NAZIR, 2011; CONRADO, 2017; CONRADO; NUNES-NETO, 2018).

Em virtude dessa falta de consenso acerca de um significado ou uma definição única e precisa de educação CTSA em todas as partes do mundo, várias abordagens, além de programas e métodos pedagógicos distintos, foram desenvolvidos no decorrer do tempo, e, após quatro décadas desde sua origem, Pedretti e Nazir (2011) descreveram em seu estudo a existência de seis vertentes, ou tendências, da educação CTSA, sendo que as autoras utilizaram a metáfora "correntes", comparando essas abordagens com um vasto oceano de ideias, princípios e práticas pedagógicas.

De acordo com as referidas autoras, essas vertentes não são mutuamente excludentes, visto que, apesar de discerníveis, passam por constantes mudanças, podendo inclusive se dissolverem ou até mesmo se fundirem para formar novas correntes. Alguns estudos, como os de Conrado (2017) e Conrado e Nunes-Neto (2018), reconhecem o quanto o entendimento dessas tendências é importante para a compreensão da diversidade de abordagens sob o slogan CTSA, bem como seus objetivos e estratégias de aplicação no âmbito da educação científica, considerando ainda que:

[...] cada corrente tem suas próprias forças e limitações. Algumas têm uma história mais longa que outras, enquanto outras refletem preocupações mais recentes. Algumas correntes também podem coexistir, se sobrepor e serem utilizadas em harmonia. Cabe aos professores, em última análise, escolher as mensagens e os métodos apropriados ao seu contexto educacional, unidade curricular ou tópico e às suas visões de mundo específicas (PEDRETTI; NAZIR, 2011, p. 619, tradução nossa) ${ }^{1}$.

\footnotetext{
1 “[...] each current has its own strengths and limitations. Some have a longer history than others, whereas others reflect more recent concerns. Some currents can also coexist, overlap, and be utilized in harmony. It is up to teachers to ultimately choose the messages and methods that are appropriate to their educational context, the curriculum unit or topic, and to their particular worldviews".
} 
Nesse contexto, é cabível comentarmos brevemente, mas de maneira geral, sobre o panorama que essas tendências representam, pois, como já ressaltado, o instrumento de avaliação elaborado neste estudo foi inspirado, a princípio, na educação CTSA por meio de QSC.

A primeira tendência apresentada por Pedretti e Nazir (2011) enfatiza a relação dos conhecimentos científicos e tecnológicos, bem como o desenvolvimento de habilidades técnicas e de pesquisa frente aos problemas sociais. No entanto, essa vertente apresenta algumas críticas, como a possibilidade de incentivar os alunos a se tornarem dependentes exclusivamente de soluções tecnológicas para todos os problemas.

A segunda vertente elencada pelas autoras focaliza a incorporação histórica e sociocultural da ciência para compreender como tais aspectos são indispensáveis na educação CTSA. Uma das principais críticas dessa vertente é o fato de ela poder, involuntariamente, reforçar alguns estereótipos e aspectos míticos da ciência, sem estabelecer uma relação com as etapas dos processos que resultaram no contexto social atual.

A terceira vertente, que, segundo as autoras, é uma das mais fortes na perspectiva CTSA, ressalta a importância do raciocínio lógico e da argumentação na tomada de decisões diante dos problemas sociocientíficos, refletindo de forma responsável e com cidadania. Entre as principais críticas dessa tendência, destaca-se a limitação atribuída ao raciocínio lógico e aos aspectos epistemológicos, desconsiderando a necessidade de atender às demandas emocionais, estéticas e culturais dos alunos na tomada de decisões (PEDRETTI; NAZIR, 2011; CONRADO, 2017; CONRADO; NUNES-NETO, 2018).

Continuando esta discussão, é importante lembrar que as próximas vertentes foram desenvolvidas a partir das críticas levantadas às três primeiras, conforme apontam Conrado e Nunes-Neto (2018), sendo que a quarta enfatiza principalmente o reconhecimento da ciência por meio de valores, como o caráter, a ética e o desenvolvimento moral e cognitivo, que interferem no posicionamento e nas atitudes dos alunos. Porém, uma crítica sobre esta tendência é a falta fundamental de consenso sobre valores universais e o relativismo ético que circunda cada contexto socioambiental.

Por sua vez, a quinta tendência enfatiza uma abordagem sociológica da educação científica na qual a ciência não se sobrepõe às demais formas de conhecimentos existentes em diferentes contextos socioculturais. A principal crítica dessa corrente sociocultural se manifesta pela dificuldade de estabelecer correlações entre a ciência e os conhecimentos alternativos dos estudantes, que muitas vezes podem ter sentidos contrários ou serem abordados de maneira superficial.

Enfim, a última vertente preconiza o ativismo na formação do senso de justiça social e ambiental para que os alunos possam desenvolver responsabilidade cívica e agir em virtude da solução dos problemas da atualidade. Uma das principais preocupações apontadas nesta vertente é a possível existência de um paradoxo ideológico, dificultando, assim, a padronização democrática do que seria justo e correto na educação CTSA (PEDRETTI; NAZIR, 2011; CONRADO, 2017; CONRADO; NUNES-NETO, 2018).

Reconhecemos a contribuição de Pedretti e Nazir (2011) pelos esforços em identificar e caracterizar essas correntes na educação do CTSA, bem como suas orientações teóricas e práticas para o ensino de ciências nos mais variados contextos em que essa abordagem continua a se desenvolver. No entanto, as próprias autoras apontam que, recentemente, outros movimentos têm evoluído no campo da educação científica e, por sua vez, podem compartilhar 
princípios, visões e pedagogias similares com a educação CTSA, como o uso das QSC, por exemplo.

Santos e Mortimer (2002) corroboram essa discussão ao afirmarem que nem todas as propostas curriculares de ensino denominadas como CTSA estão apropriadamente interrelacionadas com a ciência, a tecnologia, a sociedade e o ambiente e, por isso, mesmo que intencionalmente, podem gerar nos alunos uma visão corrompida sobre a natureza desses conhecimentos. Nesse sentido, algumas pesquisas (ZEIDLER et al., 2005; ZEIDLER; NICHOLS, 2009) corroboram essa discussão ao argumentarem que a abordagem CTSA, por si só, não trata diretamente do desenvolvimento moral, ético e político dos estudantes, na medida em que as QSC podem contribuir com esses aspectos, uma vez que têm como elemento complementar o fato de estimularem o raciocínio cognitivo e moral na avaliação de questões éticas e sociais contemporâneas que requerem conhecimento científico para a tomada de decisões informadas.

\subsection{O ensino inspirado nas QSC: um horizonte além da educação CTSA}

Como foi discutido, o uso de QSC refere-se a uma estratégia pedagógica inovadora que, assim como a educação CTSA, objetiva capacitar os alunos para lidarem com questões baseadas na ciência e tomarem decisões em conformidade com os princípios éticos e a construção de juízos morais sobre tópicos científicos por meio da interação social e do discurso (ZEIDLER et al., 2005; ZEIDLER; NICHOLS, 2009; CONRADO, 2017).

Nesse âmbito, o ensino por QSC é importante porque contempla tudo o que a educação CTSA tem a oferecer, sobretudo as dimensões éticas da ciência, o raciocínio moral e o desenvolvimento emocional do aluno (ZEIDLER et al., 2005; ZEIDLER; NICHOLS, 2009). Num contexto contemporâneo, Conrado e Nunes-Neto (2018) definem QSC como problemas ou situações geralmente complexos e de natureza controversa que podem ser utilizados para promover uma educação científica contextualizadora que permita:

\footnotetext{
[...] uma abordagem de conteúdos inter ou multidisciplinares, sendo os conhecimentos científicos fundamentais para a compreensão e a busca de soluções para estes problemas. Além do conhecimento científico, particularmente, conhecimentos de filosofia (sobretudo de ética) e história são relevantes e geralmente mobilizados na abordagem das QSC, além de diferentes habilidades, valores e atitudes, pois a proximidade com situações do contexto real aumenta o interesse, o diálogo e o engajamento dos estudantes. (CONRADO; NUNES-NETO, 2018, p. 87).
}

Conrado e Nunes-Neto (2018) consideram ainda que o ensino a partir de QSC pode corresponder a uma metodologia ativa ou participativa, que, além dos conhecimentos científicos, contribui com a mobilização de valores, habilidades e atitudes dos estudantes perante os aspectos culturais, políticos e econômicos no contexto sociocentífico. Vale a pena lembrar que tais questões e problemáticas controversas podem afetar o crescimento intelectual dos sujeitos, sobretudo nos domínios pessoal e social, evidenciando, assim, a necessidade de desenvolver uma estrutura conceitual coerente e, ao mesmo tempo, flexível o suficiente para contextualizar com as múltiplas perspectivas éticas, morais, ambientais e culturais dos educandos (ZEIDLER et al., 2005).

Nessa perspectiva, Zeidler et al. (2005) aprimoraram uma estrutura de QSC proposta em estudo anterior (ZEIDLER; KEEFER, 2003), cuja finalidade centrava-se em abordar o 
discurso sociocientífico nos campos do crescimento psicológico, social e emocional da criança, tendo observado que a extensão e o refinamento desse modelo possibilitaram aos autores identificar potenciais linhas de pesquisa promissoras para o desenvolvimento de QSC no ensino de ciências, atendendo, desse modo, a diversos fatores que, até então, estavam inerentemente limitados ou ausentes na educação CTSA. A estrutura referida é composta por quatro importantes áreas pedagógicas essenciais para o ensino de QSC: questões de natureza científica, questões do discurso da sala de aula, questões culturais e questões baseadas em casos que englobam problemas controversos do ponto de vista sociocientífico (ZEIDLER et al., 2005; ZEIDLER; NICHOLS, 2009).

Segundo Zeidler et al. (2005), mesmo que tais elementos possam contribuir para o desenvolvimento cognitivo e moral dos alunos, há um ponto importante a se considerar, que é a incerteza sobre se o desenvolvimento e a implementação do ensino por QSC resultarão na formação de indivíduos sociopoliticamente ativos, mas algo é certo: os estudantes familiarizados com essas questões terão maior probabilidade de considerar cuidadosamente e de maneira reflexiva os aspectos morais, políticos e ambientais em suas decisões, mostrando, assim, um nível de alfabetização científica funcional.

Apesar de essa estrutura visar o raciocínio baseado em evidências para que as QSC sejam significativas e envolvidas com os alunos, Zeidler et al. (2005) apontam a possibilidade de ela não abranger todas as condições suficientes da alfabetização científica (funcionais ou de outra natureza), mas que, devido à sua criticidade, são necessárias para o ponto de partida em busca dessa alfabetização. Desse modo, uma visão geral dessas quatro questões pedagógicas (natureza científica, discurso em sala de aula, culturais e os casos baseados em problemas controversos) se faz necessária para sintetizar as linhas de pesquisa atuais e relevantes para o uso de QSC no ensino de ciências.

Diante do exposto, as questões pedagógicas de natureza científica, presentes na estrutura apresentada, revela a ênfase atribuída às crenças epistemológicas dos alunos no que diz respeito às decisões referentes à natureza da ciência e às QSC, sendo que os valores pessoais, os fatores relacionados à moralidade ou à ética e as considerações sociais assumem papel fundamental nessa tomada de decisões. Em sequência, as questões do discurso da sala de aula enfatizam o papel crucial que ele desempenha nas interações entre os estudantes e o meio sociocientífico, bem como o desenvolvimento do raciocínio moral acerca da ciência através da argumentação para lidar com evidências conflitantes relacionadas à QSC. Já as questões culturais destacam os aspectos pluralistas e sociológicos existentes nas salas de aula, além da necessidade de reconhecer e valorizar os estudantes como agentes morais ativos e intensamente envolvidos com seus próprios ambientes culturais, naturais e tecnológicos. Por fim, as questões envolvendo casos baseados em problemas sociocientíficos e controversos reforçam a necessidade de promover a formação de cidadãos cientificamente alfabetizados, à medida que os alunos se envolvem em discursos e reflexões que buscam o desenvolvimento do pensamento crítico e de habilidades de raciocínio cognitivo, ético e moral (ZEIDLER; KEEFER, 2003; ZEIDLER et al., 2005; ZEIDLER; NICHOLS, 2009).

Esses pressupostos das QSC nos serviram de inspiração para construirmos um instrumento de avaliação escolar que pudesse mensurar, nas dimensões conceituais, procedimentais e atitudinais da aprendizagem, indicativos de vulnerabilidade de adolescentes às IST/AIDS, pois, conforme esclarecem Zeidler et al. (2005), os casos baseados em problemas, juntamente com questões polêmicas, controversas e conflitantes, permitem ir além da educação CTSA e promover a consciência ética e comprometida com a resolução desses problemas nos mais variados contextos culturais. 
Finalmente, outros aspectos que merecem destaque por fortalecerem a importância de se trabalhar QSC por meio de casos e situações baseados em problemas sociais é que, além da construção de juízos morais sobre temas científicos através da interação social e do discurso, os alunos poderão ser confrontados com múltiplas perspectivas frente a esses problemas, inclusive com pontos de vista e informações discrepantes com suas próprias crenças e seus conhecimentos alternativos com os quais estão acostumados a lidar, despertando atitudes de negociar, resolver conflitos e melhorar a qualidade de seus próprios argumentos (ZEIDLER; NICHOLS, 2009). Assim, a introdução de questões baseadas em casos representa uma estratégia pedagógica diferenciada que, além das ramificações sociológicas, preconiza também aspectos psicológicos do currículo e do discurso em sala de aula, bem como o desenvolvimento moral, ético, emocional e epistemológico dos alunos (ZEIDLER et al., 2005; ZEIDLER; NICHOLS, 2009).

\section{Avaliação e desempenho escolar no ensino de ciências}

A avaliação escolar corresponde a uma temática de interesse nas diversas áreas da educação em nível mundial, sendo considerada um complexo e importante elemento do processo de ensino e aprendizagem capaz de contribuir para uma educação de qualidade e acessível a todas as pessoas (KNIJNIK; GIACOMONI; STEIN, 2014).

Nessa perspectiva, a avaliação de desempenho escolar pode ser compreendida como um processo que permite a revisão de métodos do ensino e da aprendizagem para acompanhar o desempenho acadêmico do aluno, contribuindo na identificação de aspectos críticos e fragilizados que necessitam de aprimoramento (KNIJNIK; GIACOMONI; STEIN, 2014). Corroborando esse pensamento, Tonelotto et al. (2005) apontam que o desempenho escolar representa uma maneira de analisar, nos aspectos quantitativos e qualitativos, a capacidade dos educandos em acompanhar os conteúdos propostos pela escola.

Diante dessas considerações, percebemos que a avaliação do desempenho escolar é essencial para uma educação eficiente e qualificada, pois permite determinar até que ponto os objetivos pré-estabelecidos pela educação formal são alcançados (SOUZA, 2016) e se possuem subsídios para a melhoria de possíveis inconsistências e fragilidades do processo educacional. No entanto, Selikowitz (2001) e Tonelotto et al. (2005) apontam que os resultados obtidos através dos testes de desempenho escolar não são totalmente conclusivos, podendo, assim, ser utilizados juntamente com outros instrumentos com a finalidade diagnóstica para ampliar sua utilidade na formulação de hipóteses e no reconhecimento de problemas.

Corroborando essa discussão, Bizzo (2015) aborda que a maioria dos atuais testes padronizados de escala nacional são baseados na dimensão conceitual da aprendizagem e, por isso, não são capazes de identificar os processos e as habilidades necessários para que os alunos possam ser ativamente atuantes nos aspectos sociocientíficos atuais. Nesse contexto, uma das discussões que têm ganhado destaque na atual educação científica é o pluralismo epistemológico, ou seja, as diferentes formas de explicar e conceituar o mundo, os fenômenos e os fatos científicos considerando a pluralidade de saberes (COBERN; LOVING, 2001; ELHANI; MORTIMER, 2007; SOUZA, 2016).

Desse modo, pensar num teste de rendimento escolar que contemple o pluralismo epistemológico é uma tarefa desafiadora e complexa tanto para os educadores quanto para os técnicos, gestores e demais agentes envolvidos no processo educacional e que lidam com a falta de recursos e instrumentos de mensuração apropriados para atender à diversidade cultural, e 
isso sem deixar de lado as teorias e os conceitos científicos (TONELOTTO et al., 2005; SOUZA, 2016).

\section{Percurso metodológico}

O estudo envolveu uma abordagem qualitativa e exploratória, na qual o instrumento de avaliação escolar desenvolvido foi submetido a um processo de validação de conteúdo, por meio da metodologia Delphi, e contou com a colaboração de um painel de especialistas composto por pesquisadores e professores com formação na área de ensino, majoritariamente, e a minoria na área da saúde, totalizando 19 (dezenove) especialistas, que atuaram especificamente no processo de validação de conteúdo do questionário e da Matriz de Referência. Os demais sujeitos participantes da pesquisa correspondem a adolescentes matriculados no $3^{\circ}$ ano do Ensino Médio em escolas públicas estaduais de Aracaju, que colaboraram para o processo de validação semântica do questionário e, posteriormente, para a aplicação piloto dele, totalizando 111 (cento e onze) estudantes, subdivididos em oito participantes na primeira etapa e 103 (cento e três) na segunda.

Convém ressaltar que a pesquisa está em conformidade com os princípios éticos preconizados pela Resolução $n^{\circ} 510 / 2016$ do Conselho Nacional de Saúde, que trata de pesquisas com seres humanos, e contou com a aprovação da Comissão de Ética em Pesquisa da Universidade Federal de Sergipe (UFS), sob o parecer $n^{\circ} 2.256 .567$. Assim, os sujeitos foram convidados a participar da pesquisa por livre e espontânea vontade, demonstrada através de um Termo de Consentimento Livre e Esclarecido (TCLE) redigido em forma de carta-convite, tanto para o grupo de especialistas quanto para os alunos e/ou seus responsáveis, com linguagem adequada para cada grupo de participantes. Além disso, contamos também com a anuência da Secretaria de Estado da Educação de Sergipe (SEED) e dos diretores das escolas em que os instrumentos foram aplicados.

A seguir, detalhamos os principais procedimentos traçados para a construção do instrumento de avaliação escolar proposto, além de sua fundamentação e das estratégias utilizadas nas etapas de elaboração, validação e aplicação do material e dos demais instrumentos utilizados.

\subsection{Síntese do processo de validação e aplicação piloto}

O tipo de validação escolhido para a elaboração do questionário foi a de conteúdo por ser considerada a mais apropriada para este estudo, pois, além de possibilitar o desenvolvimento de medidas adequadas em relação aos conceitos que se pretende medir e sua representatividade (PASQUALI, 1996, 2009), a execução do método Delphi, utilizado nesta etapa com a colaboração dos especialistas (juízes), ocorreu de forma simples e objetiva, o que garantiu a construção do instrumento com qualidade.

Os especialistas participaram do estudo tanto de maneira presencial quanto à distância, por meio dos recursos advindos das Tecnologias Digitais da Informação e Comunicação (TDIC), como o correio eletrônico, por exemplo. Durante esta etapa, foi caracterizado o perfil dos avaliadores e foram disponibilizados alguns documentos com as instruções e descrições dos requisitos a serem avaliados na Matriz de Referência e no questionário, para que os avaliadores pudessem informar seu nível de concordância acerca dos critérios avaliados. Esse processo de avaliação dos instrumentos ocorreu em duas etapas, sendo que, após o julgamento individual dos especialistas, com base em Westmoreland et al. (2000) e Jesus (2013), as 
questões e/ou descritores que não obtiveram um consenso de no mínimo $80 \%$ satisfatório, foram readequados conforme as recomendações e submetidos a uma segunda rodada para alcançar o consenso recomendado.

Logo após a primeira rodada do método Delphi com os especialistas, o questionário passou por uma análise semântica com a participação de oito estudantes concluintes da educação básica, objetivando, assim, verificar se o instrumento era compreensível para essa amostra representante da população-alvo, na qual procuramos analisar se as questões realmente ofereciam clareza e objetividade a eles, bem como identificar eventuais falhas ou incorreções, eliminando ambiguidades e demais inconsistências que pudessem prejudicar a compreensão dos sujeitos durante a aplicação piloto.

A aplicação piloto do questionário, por sua vez, foi realizada em uma amostra aleatória de turmas do $3^{\circ}$ ano do Ensino Médio de três escolas estaduais de Aracaju, totalizando 103 alunos e, basicamente, consistiu na aplicação do instrumento após as devidas correções, juntamente com mais dois questionários, um sociodemográfico e outro de qualidade de vida, elaborado pelo Grupo de Qualidade de Vida da Organização Mundial da Saúde e validado no Brasil por Fleck et al. (1999, 2000), o que nos permitiu, posteriormente, correlacionar os resultados e aprimorar a validação desses instrumentos de forma quantitativa, por meio de análises estatísticas (ALVES; PAGAN, 2019).

\subsection{Aproximação de QSC em um instrumento de avaliação escolar sobre IST}

As discussões sobre QSC envolvem problemas ou situações controversas nos mais variados níveis de complexidade e contribuem para melhoria da educação de maneira geral, visto que, além dos conhecimentos científicos, mobilizam uma abordagem contextualizada e multidisciplinar com valores, atitudes e habilidades essenciais para a compreensão e a solução desses problemas. Nessa perspectiva, muitos dos problemas de saúde pública [incluindo as IST] são bons exemplos de QSC na atualidade por considerarem as polêmicas relações entre CTSA nos processos de ensino e aprendizagem (CONRADO; NUNES-NETO, 2018).

Dessa forma, trabalhar questões relacionadas às IST/AIDS na escola assume um caráter social relevante, visto que podem abordar problemas sociais e econômicos que impactam na saúde coletiva e individual, sobretudo dos jovens estudantes da educação básica. Levando-se em consideração esses aspectos, a elaboração de um questionário inspirado em alguns pressupostos fundamentais das QSC contribui para que os alunos reflitam sobre sua atuação na sociedade e se sintam importantes agentes ativos no processo de prevenção das IST/AIDS, desenvolvendo, assim, o interesse por refletir criticamente e de maneira responsável suas decisões e atitudes no contexto em que estão inseridos.

Diante do exposto, foi enfatizada neste trabalho a construção de um instrumento de desempenho em ciências que contemplasse uma estruturação distinta das que são apresentadas pela maioria das avaliações em larga escala, na qual a principal estratégia inovadora se refere ao desenvolvimento de questões cujos enunciados e/ou alternativas tragam algumas características das QSC, principalmente a possibilidade de situar as questões nas esferas política, social, ética, moral e ambiental para analisar não apenas os aspectos cognitivos da ciência e, sim, dimensões conceituais, procedimentais e atitudinais da aprendizagem dos conteúdos, o que permite estabelecer relações com fatores de vulnerabilidade dos estudantes às IST/AIDS. Martins et al. (2018, p. 215) reforçam esses princípios ao concordarem que as QSC no ensino de ciências podem "viabilizar a inclusão de uma educação em saúde numa perspectiva socioecológica", objetivando, então, a emancipação dos educandos para atuarem frente às 
determinadas questões sociais e ambientais urgentes, como as relacionadas à saúde e à qualidade de vida.

\section{Resultados e discussões}

Nesta seção, serão apresentados os principais resultados e discussões acerca do processo de elaboração e validação do instrumento de avaliação escolar desenvolvido e sua aproximação com as QCS.

\subsection{Elaboração das questões: fundamentação}

Inicialmente, foi construído um protótipo de Matriz de Referência para a elaboração das questões, no qual buscamos relacionar os descritores estabelecidos em cada item com a quarta e a sexta vertentes da educação CTSA, majoritariamente, estabelecidas por Pedretti e Nazir (2011) (apresentadas no tópico "2.1" deste artigo), com as questões pedagógicas do ensino de QSC (natureza científica, discurso, culturais e casos baseados em problemas) estabelecidas por Zeidler e Keefer (2003) e aperfeiçoadas por Zeidler et al. (2005), visando, assim, constituir uma estrutura que contemplasse esses elementos sob uma abordagem pluralística, do ponto de vista epistemológico, envolvendo a temática sexualidade, especificamente sobre as IST/AIDS.

Destacamos a relevante contribuição de Conrado e Nunes-Neto (2018) ao apresentarem, sob uma óptica inovadora, um modelo teórico para abordagem de QSC no ensino de ciências, que, em sua unidade básica, articula três elementos essenciais: histórias ou casos, questões norteadoras e objetivos da aprendizagem nas dimensões conceituais, procedimentais e atitudinais. Esse modelo também nos serviu de inspiração para a construção das questões, pois, como esclarecem os autores, as propostas de ensino baseadas em QSC, quando devidamente adotadas como estratégia ou método de ensino,

\footnotetext{
[...] estimulam discussões interdisciplinares sobre um tema, geralmente, veiculado nos meios de comunicação de massa, capaz de promover argumentação; [...] explicitam implicações éticas e ambientais; [...] mobilizam conhecimentos científicos de fronteira, bem como aqueles associados à compreensão da Natureza da Ciência; [...] envolvem discussão de valores morais, interesse e opiniões; [...] e por fim, possibilitam tomada de decisão e ação dos participantes. (CONRADO; NUNESNETO, 2018, p. 88).
}

Assim como em outros estudos (ZEIDLER; KEEFER, 2003; ZEIDLER et al., 2005; CONRADO, 2017; CONRADO; NUNES-NETO, 2018), consideramos adequada a construção de questões de desempenho que se aproximassem do formato de QSC organizadas em casos elaborados como histórias próximas aos contextos socioculturais dos educandos, pois essa abordagem possibilita explanar diferentes pontos de vista, juízos de valor, crenças e interpretações, permitindo a aproximação e o engajamento dos estudantes frente aos problemas controversos. No entanto, Conrado e Nunes-Neto (2018) complementam essa discussão ao ressaltarem que o uso de caso/história de maneira isolada pode ser ineficaz para o desenvolvimento da aprendizagem de conhecimentos, valores, atitudes e habilidades, sendo então necessária a utilização de "questões norteadoras" para mediar essa interação com determinadas interfaces dos problemas sociocientíficos contidas no caso. 
Nesse contexto, o instrumento foi elaborado considerando-se que o uso de narrativas na forma de caso, juntamente com as questões norteadoras, somando-se com os objetivos da aprendizagem, definidos num modelo tridimensional dos conteúdos (conceituais, procedimentais e atitudinais), formam os três elementos da perspectiva proposta por Conrado e Nunes-Neto (2018, p. 90) sobre o uso de QSC no processo educacional, permitindo, assim, o "desenvolvimento de conhecimentos, habilidades, valores e atitudes essenciais voltados para uma formação mais integral dos sujeitos enquanto indivíduos efetivamente engajados em participação social".

Dessa forma, visando mensurar indicativos de vulnerabilidade dos jovens com relação às IST/AIDS, as questões foram contextualizadas com pequenos casos envolvendo personagens (pelo menos na maioria dos enunciados) e situações comuns do período da adolescência, emergindo, de maneira implícita, variáveis latentes acerca das dimensões atitudinais, juntamente com informações, conceitos e problemas controversos relacionados à temática, sendo criadas três categorias analíticas mediante uma revisão integrativa da literatura e com base na perspectiva de Bardin (2016), podendo indicar, com isso, o quanto o aluno poderia estar vulnerável à contaminação de IST/AIDS conforme seu nível de compreensão e os indicativos de opiniões e atitudes.

Nesse sentido, as categorias levantadas foram: 1. Criticidade e Informação; 2. Contextos de gênero e representações da adolescência; 3. Maturidade/imaturidade para lidar com a sexualidade. Para facilitar o entendimento, apresentamos o detalhamento dessas categorias no quadro a seguir, relacionando-as com os tipos de vulnerabilidade, e especificamos quais questões estão relacionadas com cada categoria.

Quadro 1 - Categorias que podem representar indicativos de vulnerabilidade às IST/AIDS entre adolescentes

\begin{tabular}{|c|c|c|c|}
\hline Categorias & Especificações & $\begin{array}{c}\text { Tipo de } \\
\text { vulnerabilidade }\end{array}$ & Questões \\
\hline $\begin{array}{l}\text { Criticidade e } \\
\text { Informação }\end{array}$ & $\begin{array}{l}\text { Refere-se à adequação ou à inadequação das informações } \\
\text { e à criticidade demonstrada pelo(a) aluno(a) a respeito da } \\
\text { sexualidade de forma geral e principalmente sobre } \\
\text { medidas protetivas contra as IST, seus sintomas e seu } \\
\text { tratamento. }\end{array}$ & $\begin{array}{l}\text { Individual } \\
\text { Social }\end{array}$ & $\begin{array}{l}01,02,04 \\
05,06,07 \\
\text { e } 10\end{array}$ \\
\hline $\begin{array}{l}\text { Contextos de } \\
\text { gênero e } \\
\text { representações } \\
\text { da adolescência }\end{array}$ & $\begin{array}{l}\text { Relacionada aos contextos sociais sexistas e à concepção } \\
\text { equivocada de a adolescência ser uma fase rotulada como } \\
\text { invulnerável, que podem dificultar ações e tomadas de } \\
\text { decisões protetivas. }\end{array}$ & $\begin{array}{c}\text { Individual } \\
\text { Social } \\
\text { Programática }\end{array}$ & $\begin{array}{l}01,05,08 \\
\text { e } 09\end{array}$ \\
\hline $\begin{array}{c}\text { Maturidade/ } \\
\text { imaturidade } \\
\text { para lidar com a } \\
\text { sexualidade }\end{array}$ & $\begin{array}{l}\text { Decorrente do nível de maturidade e/ou experiência do(a) } \\
\text { adolescente para lidar com diferentes situações } \\
\text { envolvendo sexualidade, como dificuldade de negociar } \\
\text { com o(a) parceiro(a) sobre medidas de proteção contra as } \\
\text { IST, bem como medo e/ou vergonha de buscar ajuda. }\end{array}$ & $\begin{array}{l}\text { Individual } \\
\text { Social }\end{array}$ & $\begin{array}{c}03,07,08 \\
09 \text { e } 10\end{array}$ \\
\hline
\end{tabular}

Fonte: Elaborado pelos autores (2019). 
Quanto a esses possíveis indicativos de vulnerabilidade, é válido ressaltar que, no âmbito da educação em saúde, assim como nas ciências sociais, os instrumentos de produção, coleta e análise de dados geralmente são compostos por variáveis não mensuráveis diretamente, denominadas de variáveis latentes, percebidas de forma indireta por meio de indicadores observáveis, como itens de uma escala de avaliação psicológica ou de comportamento e atitudes. Com efeito, as variáveis latentes podem ser consideradas hipotéticas ou teóricas, podendo ser representadas por outros indicadores, como, por exemplo, satisfação, opinião, preconceito, afetividade, beleza etc., resultando numa medida razoavelmente precisa da atitude dos sujeitos envolvidos (HAIR et al., 2005).

Em virtude disso, a primeira versão do instrumento de medida foi construída pelo pesquisador e contou com a contribuição de mais duas pesquisadoras com experiência na área de ensino e elaboração de testes de desempenho escolar, garantindo, dessa forma, maior qualidade e diversificação de opiniões sobre as questões desenvolvidas. Essa versão inicial foi composta por um texto central norteador relacionado ao tema e mais de 12 (doze) questões objetivas, por meio dos quais, de maneira intercalada, buscamos abordar as categorias citadas no Quadro 1 e relacioná-las com as dimensões conceitual, procedimental e atitudinal.

Após novas discussões e reflexões, optamos por simplificar o questionário, tendo em vista o quantitativo elevado de textos e a complexidade das temáticas abordadas, por isso o texto norteador foi suprimido, juntamente com duas questões, resultando, assim, numa versão mais objetiva, composta por 10 (dez) questões, para que pudesse ser submetida ao processo de validação. A logística e a estruturação desse questionário não priorizaram avaliar exclusivamente a aprendizagem cognitiva e conceitual dos alunos respondentes e, sim, outras dimensões do conteúdo para que possam ser analisadas na possível relação com diferentes níveis de vulnerabilidade.

Foram adotados e adaptados alguns critérios referentes ao potencial de predição das questões, conforme o modelo elaborado pelo Grupo de Pesquisa Educação Matemática e Ensino de Ciências (GPEMEC), da UFS, entre eles: organização e quantidade dos textos de cada enunciado e alternativas; objetividade e quantidade de termos técnicos presentes nas questões e/ou alternativas; e qualidade de imagens utilizadas. Tais critérios são importantes porque o excesso de termos técnicos, uma linguagem inadequada para os respondentes destinados e questões longas e com textos distribuídos de maneira diferente nas alternativas podem induzir as respostas dos alunos ou até mesmo deixá-los confusos.

Neste estudo, os critérios foram denominados, respectivamente, de: organização; objetividade; e imagens, e, além deles, criamos mais quatro critérios que fundamentaram os descritores da Matriz de Referência e, consequentemente, contribuíram para a elaboração e a validação das questões, a saber: caracterização; relevância; vulnerabilidade; e neutralidade. As descrições de todos eles estão representadas no Quadro 2.

Quadro 2 - Critérios para potencial de predição e validação de conteúdo das questões

\begin{tabular}{|cc|}
\hline CRITÉRIO & ESPECIFICAÇ̃̃O \\
\hline & O enunciado da questão e/ou suas alternativas apresentam elementos que se aproximam \\
& a uma QSC, como situações/problemas controversos/polêmicos, que envolvem \\
Caracterização & conhecimentos científicos, bem como o envolvimento de valores morais, éticos e \\
& socioculturais que possibilitam identificar possíveis opiniões dos participantes. \\
\end{tabular}




\begin{tabular}{|c|c|}
\hline Relevância & $\begin{array}{l}\text { A questão e/ou suas alternativas envolvem discussões importantes sobre uma ou mais IST } \\
\text { e algum dos contextos vulnerabilizantes, como: } 1 \text {. Desinformação e/ou falta de criticidade } \\
\text { do(a) aluno(a) sobre sexualidade e IST; } 2 \text {. Contexto sexista que dificulta tomadas de } \\
\text { decisões protetivas; } 3 \text {. Concepção social da adolescência ser uma fase rotulada como } \\
\text { invulnerável; 4. Inexperiência e/ou imaturidade do(a) adolescente em lidar com situações } \\
\text { envolvendo sexualidade, bem como medo e/ou vergonha de buscar ajuda. 5. Dificuldade } \\
\text { de negociar com o(a) parceiro(a) sobre medidas de proteção contra as IST. }\end{array}$ \\
\hline Vulnerabilidade & $\begin{array}{l}\text { A resposta e as alternativas permitem identificar posições que indicam maior ou menor } \\
\text { distanciamento da vulnerabilidade do estudante às IST. }\end{array}$ \\
\hline Neutralidade & $\begin{array}{l}\text { O enunciado da questão não é tendencioso e apresenta distribuição equilibrada dos } \\
\text { diferentes pontos de vista, de modo a não direcionar a resposta do respondente. }\end{array}$ \\
\hline Organização & $\begin{array}{l}\text { Os textos das alternativas da questão estão devidamente organizados e estruturados de } \\
\text { maneira uniforme, com quantidade de texto parecida, para não influenciar as respostas. }\end{array}$ \\
\hline Objetividade & $\begin{array}{l}\text { Apresenta linguagem clara, acessível, com poucos termos técnicos e de fácil compreensão } \\
\text { para o público esperado (alunos do } 3^{\circ} \text { ano do Ensino Médio). }\end{array}$ \\
\hline Imagens & $\begin{array}{l}\text { Apresenta elementos visuais (imagens ou figuras) relacionados ao problema da questão } \\
\text { que possam despertar a motivação e/ou a curiosidade dos respondentes. }\end{array}$ \\
\hline
\end{tabular}

Fonte: Elaborado pelos autores (2019).

Assim, o instrumento de avaliação em ciências construído nesta pesquisa corresponde a um importante produto tecnológico para o desempenho escolar de atitudes, sem a intenção de testar os conhecimentos dos alunos sobre os temas abordados e, sim, estabelecer uma reflexão dos dados obtidos com outros elementos não cognitivos da aprendizagem. Conforme Pagan (2009), testes dessa magnitude poderão ser utilizados em diferentes contextos e por outros pesquisadores, submetendo-se a críticas construtivas para aprimorá-los ou adequá-los a outras realidades.

\subsection{Caracterização do painel de especialistas}

Considerando-se que o instrumento construído envolve, explícita ou implicitamente, temas diversificados na área de educação em saúde, psicometria, psicologia social, entre outros, 
consideramos importante contar com a participação de professores da área das Ciências da Natureza e suas Tecnologias, bem como de profissionais da área da saúde, para alcançar uma maior pluralidade de ideias, opiniões e fundamentação na elaboração das questões.

Desse modo, como podemos perceber na Tabela 1, a seguir, a formação do painel de especialistas contemplou profissionais com formações e áreas de atuação diferentes, não ficando restrito somente a educadores ou profissionais de saúde e, sim, possuindo uma distribuição diversificada e relativamente equilibrada entre esses profissionais. Da mesma forma, outros segmentos, como a rede privada e o sistema de saúde, também foram contemplados, favorecendo, assim, uma maior abrangência de opiniões e qualificações para análise e aprimoramento dos instrumentos validados.

Tabela 1 - Caracterização dos especialistas quanto à formação, à titulação e à faixa etária

\begin{tabular}{ccc}
\hline CARACTERÍSTICAS & $\mathbf{f}_{\mathbf{i}}$ & $\%$ \\
\hline Formação & & \\
Licenciatura em Biologia & 8 & 42,1 \\
Licenciatura em Química & 8 & 42,1 \\
Bacharel em Psicologia & 1 & 5,3 \\
Bacharel em Medicina & 2 & 10,5
\end{tabular}

Total 190

Titulação

Doutor(a)

4

Mestre

6

31,5

Mestrado em andamento

8

Especialista

1

Total $19 \quad 100$

Faixa etária

entre 20 a 30 anos

11

entre 31 a 40 anos

$5 \quad 26,3$

entre 41 a 50 anos

2

10,5

entre 51 a 60 anos

1

5,3

Total

19

100

Fonte: Elaborada pelos autores segundo dados levantados na pesquisa (2019). 
Como podemos observar na Tabela 1 , houve uma considerável diversidade do grupo de especialistas que participaram do processo de validação, notando-se que a maioria $(84,2 \%)$ correspondeu a profissionais com formação diretamente relacionada à docência, sendo igualmente distribuída por licenciados em Ciências Biológicas e em Química (42,1\% cada), e os demais profissionais $(15,8 \%)$ com formação na área da saúde, especificamente, dois médicos $(10,5 \%)$ e uma psicóloga $(5,3 \%)$.

No que se refere ao tempo de atuação profissional, bem como ao tipo de instituição e à área dos especialistas, foi observado que a maioria, 12 (doze), possui tempo de atuação profissional de até 5 (cinco) anos $(63,2 \%$ ), seguida de 3 (três) avaliadores com tempo de atuação entre 6 (seis) a 10 (dez) anos (15,8\%), dois entre 11 (onze) a 15 (quinze) anos (10,5\%) e mais dois que atuam profissionalmente há pelo menos 16 (dezesseis) a 20 (vinte) anos (10,5\%). A maioria desses especialistas, ou seja, 7 (sete) (36,9\%), atuam no Ensino Superior (docência e pesquisa), enquanto 5 (cinco) avaliadores (26,3\%) referiram atuar na Educação Básica, e 3 (três) $(15,8 \%)$ declararam atuar ou já atuaram tanto no Ensino Superior quanto na Educação Básica. Além desses, 4 (quatro) (21\%) avaliadores atuam em outras áreas diferentes das que foram citadas, sendo que 2 (dois) (10,5\%) atuaram como pesquisadores de iniciação científica, 1 (um) $(5,3 \%)$ atua como técnico de laboratório e 1 (um) $(5,3 \%)$ como médico da Atenção Primária à Saúde (APS). Quanto ao tipo de instituição, por sua vez, a maioria atua em instituições públicas $(68,4 \%)$, o restante em instituições privadas $(15,8 \%)$, e uma parcela desses juízes atua nessas duas categorias $(15,8 \%)$.

\subsection{Algumas considerações acerca dos resultados do processo de validação}

Conforme discutido nas seções anteriores, a metodologia Delphi foi utilizada para que o grupo de especialistas avaliasse o instrumento desenvolvido. Cada item deveria alcançar o consenso mínimo de $80 \%$ de concordância referente ao conteúdo e aos demais constructos teóricos mensurados. Assim, para aqueles que não alcançaram o nível esperado de concordância, foi realizada uma segunda rodada de avaliação, buscando-se o grau de conformidade definido.

O questionário construído no decorrer da pesquisa resultou em 10 (dez) questões objetivas, compostas por quatro alternativas cada uma, cujo objetivo foi mensurar diferentes indicativos de vulnerabilidades do público adolescente às IST/AIDS, e por meio do qual propusemos abordar nas questões aspectos que se aproximassem de algumas características das QSC, como envolvimentos de casos/assuntos polêmicos e/ou controversos contextualizados e relacionados a fatores sociais, políticos, éticos e morais, para identificar possíveis opiniões e atitudes dos respondentes frente aos conteúdos conceituais, procedimentais e atitudinais da aprendizagem.

Nesse sentido, por meio de uma escala do tipo Likert de quatro pontos (discordo totalmente, discordo, concordo e concordo totalmente), os especialistas puderam julgar cada item do questionário com base nos critérios descritos no Quadro 2. Vale ressaltar que, para fins de concordância e validação, consideramos satisfatórios os itens com requisitos julgados em "concordo" e "concordo totalmente", e, da mesma forma, os itens julgados como "discordo totalmente" e "discordo" foram considerados insatisfatórios. Os resultados da primeira rodada estão apresentados na Tabela 2. 
Tabela 2 - Consolidação dos resultados obtidos na primeira etapa de validação, conforme julgamento dos juízes avaliadores

\begin{tabular}{|c|c|c|c|c|c|c|c|c|c|c|c|c|c|c|}
\hline \multirow{3}{*}{ 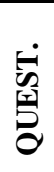 } & \multicolumn{14}{|c|}{ REQUISITOS } \\
\hline & \multicolumn{2}{|c|}{ Caracterização } & \multicolumn{2}{|c|}{ Relevância } & \multicolumn{2}{|c|}{ Vulnerabilidade } & \multicolumn{2}{|c|}{ Neutralidade } & \multicolumn{2}{|c|}{ Organização } & \multicolumn{2}{|c|}{ Objetividade } & \multicolumn{2}{|c|}{ Imagem } \\
\hline & I & $\mathbf{S}$ & I & $\mathbf{S}$ & I & $\mathbf{S}$ & I & $\mathbf{S}$ & I & $\mathbf{S}$ & I & $\mathbf{S}$ & I & $\mathbf{S}$ \\
\hline 01 & $5,3 \%$ & $94,7 \%$ & - & $100 \%$ & - & $100 \%$ & $21,1 \%$ & $78,9 \%$ & - & $100 \%$ & - & $100 \%$ & 10,5 & $89,5 \%$ \\
\hline 02 & $5,3 \%$ & $94,7 \%$ & - & $100 \%$ & - & $100 \%$ & $5,3 \%$ & $94,7 \%$ & - & $100 \%$ & $5,3 \%$ & $94,7 \%$ & $5,3 \%$ & $94,7 \%$ \\
\hline $\mathbf{0 3}$ & $15,8 \%$ & $84,2 \%$ & $5,3 \%$ & $94,7 \%$ & - & $100 \%$ & $5,3 \%$ & $94,7 \%$ & - & $100 \%$ & - & $100 \%$ & $21,1 \%$ & $78,9 \%$ \\
\hline 04 & $5,3 \%$ & $94,7 \%$ & - & $100 \%$ & - & $100 \%$ & $5,3 \%$ & $94,7 \%$ & - & $100 \%$ & - & $100 \%$ & $5,3 \%$ & $94,7 \%$ \\
\hline 05 & $15,8 \%$ & $84,2 \%$ & - & $100 \%$ & $5,3 \%$ & $94,7 \%$ & $15,8 \%$ & $84,2 \%$ & - & $100 \%$ & - & $100 \%$ & $21,1 \%$ & $78,9 \%$ \\
\hline 06 & $15,8 \%$ & $84,2 \%$ & $5,3 \%$ & $94,7 \%$ & - & $100 \%$ & $5,3 \%$ & $94,7 \%$ & $5,3 \%$ & $94,7 \%$ & - & $100 \%$ & 10,5 & $89,5 \%$ \\
\hline 07 & 10,5 & $89,5 \%$ & - & $100 \%$ & - & $100 \%$ & $5,3 \%$ & $94,7 \%$ & - & $100 \%$ & - & $100 \%$ & $5,3 \%$ & $94,7 \%$ \\
\hline 08 & $15,8 \%$ & $84,2 \%$ & - & $100 \%$ & - & $100 \%$ & $5,3 \%$ & $94,7 \%$ & - & $100 \%$ & - & $100 \%$ & $5,3 \%$ & $89,5 \%$ \\
\hline 09 & $15,8 \%$ & $84,2 \%$ & - & $100 \%$ & $5,3 \%$ & $94,7 \%$ & $5,3 \%$ & $94,7 \%$ & - & $100 \%$ & - & $100 \%$ & - & $100 \%$ \\
\hline 10 & $21,1 \%$ & $78,9 \%$ & $5,3 \%$ & $94,7 \%$ & - & $100 \%$ & $5,3 \%$ & $94,7 \%$ & $5,3 \%$ & $94,7 \%$ & $5,3 \%$ & $89,5 \%$ & - & $100 \%$ \\
\hline
\end{tabular}

Fonte: Elaborada pelos autores segundo dados levantados na pesquisa (2019).

Legenda: $\mathrm{I}$ = Insatisfatório; $\mathrm{S}=$ Satisfatório.

De maneira geral, podemos observar que praticamente todos os itens do questionário apresentaram julgamento satisfatório sobre os requisitos avaliados, pois somente as questões de número 1, 3, 5 e 10 receberam avaliação inferior a $80 \%$ de conformidade em apenas um de seus critérios, a saber: neutralidade; imagem; imagem; e caracterização, respectivamente. Por esse motivo, tais questões foram readequadas por apresentarem esses elementos insatisfatórios em sua estrutura. Após essas alterações, todas as 10 (dez) questões obtiveram o consenso satisfatório, concretizando-se, assim, a validação do questionário.

Para facilitar a consulta da versão final desse instrumento ${ }^{2}$, na Figura 1, a seguir, é apresentado um 'QR Code' (código QR - Quick Response) que permitirá acesso ao questionário validado.

\footnotetext{
${ }^{2}$ Disponível em: https://drive.google.com/file/d/1 AgqfmcchQOr6nNBEwaEURuSKilFtEnzZ/view.
} 
Figura $1-Q R$ Code do questionário validado na pesquisa

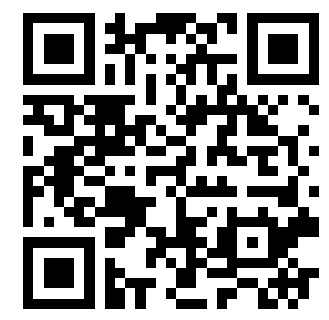

Fonte: Elaborado pelos autores (2019).

A seguir, com o intuito de mostrar de maneira mais objetiva as opiniões dos especialistas manifestadas durante o processo de validação, apresentamos algumas narrativas das falas desses pesquisadores, que também foram denominados de juízes:

\begin{abstract}
Na minha opinião, as questões estão bem elaboradas, com escrita clara e em sua maioria bem objetivas. Fomentam a reflexão do respondente no momento em que lerem a questão, além de proporcionar uma relação entre os possíveis conhecimentos dos mesmos acerca das IST e os posicionamentos perante situações cotidianas onde esses conhecimentos sejam utilizados para a tomada de decisões que possam contribuir para o cuidado com o próprio corpo e a disseminação desses posicionamentos aos demais jovens que convivam com eles... Gostei também das imagens, que em geral estão provocativas, não trazendo exatamente o que é dito no enunciado, mas ampliando o espectro de reflexão e trazendo mais elementos. Muito bom! (Juiz 18).
\end{abstract}

Diante de tudo que foi observado, considero que o questionário em análise encontrase condizente com a proposta do estudo e configura-se num instrumento relevante para a coleta de dados (Juíza 19).

As narrativas do Juiz 18 e da Juíza 19 retratam bem, porém de forma generalizada, a opinião dos especialistas acerca das questões avaliadas. Entretanto, vale ressaltar que alguns avaliadores, como o Juiz 10, por exemplo, que trabalham diretamente com as vertentes da educação CTSA e da QSC, levantaram algumas críticas importantes sobre o instrumento, sendo que, na visão desses especialistas, o requisito "caracterização" não se fez presente na maioria das questões, e, assim, os itens elaborados não correspondem à QSC. Por outro lado, a Juíza 11, que também desenvolve pesquisas sobre a temática CTSA e QSC, mostrou uma visão mais positiva diante da avaliação do questionário quanto ao requisito "caracterização":

Percebo que o principal objetivo da sua pesquisa não é somente analisar a vulnerabilidade das questões relacionadas à IST, mas também validar as suas questões como sendo uma QSC. Apesar das questões apresentarem algumas das características das questões sociocientíficas, elas não são consideradas como tal. Reconheço a tentativa de aproximar as questões a uma QSC, mas as características apresentadas não são suficientes para formalizá-las, pois as QSC não apresentam uma resposta certa, mas todas as suas questões possuem uma resposta coerente, clara e bem objetiva... Agora, se o seu objetivo é somente mensurar os indicativos de vulnerabilidades às IST, as questões estão excelentes (Juiz 10). 
Na minha percepção, o questionário está muito bem elaborado e organizado. Objetivo, conciso e direto... A vacinação é uma QSC bem atual, assim como a religião é um tema recorrente quando discutimos QSC, pois geralmente trabalhar com QSC requer discussão sobre aspectos morais e éticos, por isso considero importante a forma que esses temas foram problematizados nas questões e sua relação com as IST, já que o uso da camisinha muitas vezes ainda é considerado um tabu na sociedade (Juíza 11).

É importante frisar que, de fato, o objetivo do instrumento desenvolvido neste estudo não foi construir um questionário com QSC e, sim, como já ressaltado, tentar trazer, no enunciado e/ou nas alternativas das questões, alguma aproximação com certos aspectos característicos das QSC, principalmente no que se refere à problematização de temas controversos e conflitantes relacionados à sexualidade, em articulação com fatores políticos, socioculturais e ambientais, os quais demandam possíveis tomadas de decisões dos indivíduos conforme seus valores éticos e morais, nesse caso, mais especificamente, relacionando com indicativos de vulnerabilidade às IST. Portanto, as falas dos avaliadores, apesar de críticas, ainda assim nos indicam atendimento aos objetivos propostos nesta pesquisa.

\section{Algumas considerações}

Embora a avaliação do desempenho escolar seja essencial para uma educação eficiente e qualificada, ainda é notável a existência de um elevado quantitativo de instrumentos de avaliação padronizados com base apenas na dimensão conceitual da aprendizagem, sem reconhecer as dimensões procedimentais e atitudinais, nem os demais processos e as habilidades necessárias para que os alunos possam ser ativamente atuantes nos contextos sociocientíficos. Os modelos tradicionais de avaliação não suprem as necessidades da formação humana, por isso enfatizamos a importância de envolver aspectos sociais, afetivos e demais habilidades não cognitivas na formação dos indivíduos, pois tais elementos contribuem significativamente para o desenvolvimento da identidade, do caráter, da autonomia e para a tomada de decisões conscientes e responsáveis por parte dos educandos.

Nesse sentido, foram propostas a construção e a análise de um instrumento de avaliação escolar inspirado em alguns componentes das QSC, para que pudéssemos identificar diferentes níveis de vulnerabilidade às IST/AIDS entre os adolescentes, segundo o modelo socioecológico de saúde. Desse modo, o presente estudo mostrou ser relevante do ponto de vista tecnológico, na medida em que construiu e validou um teste de desempenho capaz de mensurar indicativos de vulnerabilidade para que, em outros estudos, seja possível estabelecer correlações com outras condições humanas, trazendo, assim, contribuições para o campo do ensino de ciências.

Reforçamos que o instrumento desenvolvido não se referiu à construção de um questionário com QSC, mas, sim, à tentativa de trazer algumas aproximações com seus aspectos, como a problematização de temas controversos e conflitantes relacionados à sexualidade, juntamente com a discussão de fatores políticos, socioculturais e ambientais frente à tomada de decisões com base em valores éticos e morais, considerando também várias tendências da educação CTSA. Essa aproximação ainda foi tímida, e é sugerida a continuidade de estudos situados na interface entre os campos da avaliação e das QSC. Enfim, tendo em vista que não existem instrumentos definitivos e perfeitos, sobretudo no que se refere ao âmbito da avaliação educacional, ressaltamos que, apesar de o instrumento construído ter sido considerado válido e fidedigno, ele poderá servir de inspiração e/ou até mesmo ser aprimorado em novos estudos. 


\section{Referências}

ALVES, M. M. S.; PAGAN, A. A. Correlação entre equilíbrio emocional e vulnerabilidade às IST/AIDS num estudo sobre desempenho escolar com adolescentes. Revista de Educação Pública, v. 28, n. 69, p. 793-819, set. 2019. Disponível em: http://periodicoscientificos.ufmt.br/ojs/index.php/educacaopublica/article/view/7896. Acesso em: 04 out. 2019.

BIZZO, N. Avaliações em larga escala: breve panorama e perspectivas. In: PAGAN, A. A.; TOLENTINO-NETO, L. C. B. (orgs.). Desempenho escolar inclusivo. 1. ed. Curitiba-PR: CRV, 2015. cap. 16, p. 207-216.

COBERN, W. W.; LOVING, C. C. Defining science in a multicultural world: implications for science education. Science Education, v. 85, n. 1, p. 50-67, 2001.

CONRADO, D. M.; NUNES-NETO, N. Questões sociocientíficas e dimensões conceituais, procedimentais e atitudinais dos conteúdos no ensino de ciências. In: (orgs.). Questões sociocientíficas: fundamentos, propostas de ensino e perspectivas para ações sociopolíticas. Salvador: EDUFBA, 2018. cap. 3, p. 77-118.

EL-HANI, C. N.; MORTIMER, E. F. Multicultural education, pragmatism, and the goals of science teaching. Revista Cultural Studies of Science Education, v. 2, i. 3, p. 657-702, 2007.

FERREIRA, R. L. et al. Educação em saúde numa perspectiva socioecológica: uma proposta para o Ensino Médio compatível com o tempo presente. Revista da SBEnBio, Campinas, $n$. 7, p. 6576-6587, 2014.

FLECK, M. P. A. et al. Aplicação da versão em português do instrumento abreviado de avaliação da qualidade de vida "WHOQOL-bref". Revista de Saúde Pública, v. 34, n. 2, p. 178-83, 2000.

FLECK, M. P. A. et al. Aplicação da versão em português do instrumento de avaliação da qualidade de vida da Organização Mundial da Saúde (WHOQOL-100). Revista de Saúde Pública, v. 33, n. 2, p. 198-205, 1999.

HAIR, J. F. et al. Análise multivariada de dados. 5. ed. Porto Alegre: Bookman, 2005. 593p.

JESUS, E. M. S. Desenvolvimento e validação de conteúdo de um instrumento para avaliação da assistência farmacêutica em hospitais de Sergipe. 2013. 152p. Dissertação (Mestrado em Ciências Farmacêuticas) - Universidade Federal de Sergipe, São Cristóvão-SE, 2013.

KNIJNIK, L. F.; GIACOMONI, C.; STEIN, L. M. Teste de desempenho escolar: um estudo de levantamento. Psico-USF, Bragança Paulista, v. 18, n. 3, p. 407-416, set./dez. 2013.

MACHADO, C.; ALAVARSE, O. M.; ARCAS, P. H. Sistemas estaduais de avaliação: interfaces com qualidade e gestão da educação. RBPAE, v. 31, n. 3, p. 667-680, set./dez. 2015. Disponível em: http://seer.ufrgs.br/index.php/rbpae/article/view/63800/37029. Acesso em: 11 mar. 2018. 
MARTINS, L. B. M. et al. Fatores associados ao uso de preservativo masculino e ao desconhecimento sobre DST/AIDS em adolescentes de escolas públicas e privadas do município de São Paulo, Brasil. Cad. Saúde Pública, v. 22, n. 2, p. 315-323, 2006.

MARTINS, L. Saúde no Contexto Educacional: as abordagens de saúde em um livro didático de biologia largamente usado no ensino médio brasileiro. 2011. 174 f. Dissertação (Ensino, Filosofia e História das Ciências) - Universidade Federal da Bahia, Salvador, 2011.

MARTINS, L. et al. Doenças de chagas a partir de questões sociocientíficas na educação em saúde. In: CONRADO, D. M.; NUNES-NETO, N. (orgs.). Questões sociocientíficas: fundamentos, propostas de ensino e perspectivas para ações sociopolíticas. Salvador: EDUFBA, 2018. cap. 8, p. 213-229.

PAGAN, A. A. Ser (animal) humano: evolucionismo e criacionismo nas concepções de alguns graduandos em Ciências Biológicas. 2009. 228 p. Tese (Doutorado em Educação) Faculdade de Educação da Universidade de São Paulo, São Paulo, 2009.

PASQUALI, L. Psicometria. Rev. Esc. Enferm. USP, v. 43 (Esp.), p. 992-999, 2009.

PASQUALI, L. Teoria e métodos de medida em ciências do comportamento. Brasília: Laboratório de Pesquisa em Avaliação e Medida, Instituto de Psicologia, UnB: INEP, 1996. $432 \mathrm{p}$.

SANTOS, W. L. P.; MORTIMER, E. F. Uma análise de pressupostos teóricos da abordagem C-T-S (Ciência - Tecnologia - Sociedade) no contexto da educação brasileira. Rev. Ensaio, Belo Horizonte, v. 02, n. 02, p. 110-132, dez., 2002.

SELIKOWITZ, M. Dislexia e outras dificuldades de aprendizagem. RevinteR, Rio de Janeiro, p. 49-50, 2001.

SOUZA, S. S. Validação externa baseada no pluralismo epistemológico: um estudo sobre o tema "ser humano" e "saúde" no Estado de Sergipe. 2016. 86 p. Dissertação (Mestrado em Ensino de Ciências e Matemática) - Universidade Federal de Sergipe, São Cristóvão-SE, 2016.

SOUZA, S. S. et al. Uma nova abordagem para o desempenho escolar em ciências: vida e ambiente; ser humano e saúde. 1. ed. Curitiba-PR: CRV, 2017. 264p.

STRIEDER, R. B. Abordagem CTS e Ensino Médio: espaços de articulação. 2008. 203p. Dissertação (Mestrado em Ensino de Ciências) - Faculdade de Educação da Universidade de São Paulo, São Paulo, 2008.

TONELOTTO, J. M. F. et al. Avaliação do desempenho escolar e habilidades básicas de leitura em escolares do ensino fundamental. Avaliação Psicológica, v. 4, n. 1, p. 33-43, 2005

WESTMORELAND, D. et al. Consensual Validation of clinical practice model guidelines. J. Nurs. Care Quality, v. 14, n. 4, p. 16-27, 2000.

ZABALA, A. A prática educativa: como ensinar. Tradução Ernani F. da F. Rosa. Porto Alegre: Artmed, 1998. 
ZEIDLER, D. L.; KEEFER, M. The role of moral reasoning and the status of socioscientific issues in science education: Philosophical, psychological and pedagogical considerations. In: D. L. Zeidler (Ed.). The role of moral reasoning and discourse on socioscientific issues in science education. The Netherlands: Kluwer Academic Press, 2003. p. 7-38.

ZEIDLER, D. L.; NICHOLS, B. H. Socioscientific Issues: Theory and Practice. Journal of Elementary Science Education, v. 21, n. 2, p. 49-58, 2009.

ZEIDLER, D. L. et al. Beyond STS: A Research-Based Framework for Socioscientific Issues Education. Wiley InterScience, p. 357-377, mar. 2005.

Recebido em março de 2020.

Aprovado em maio de 2020. 